\title{
Can adolescence affect maternal and neonatal pregnancy outcomes?
}

\begin{abstract}
Aim: To evaluate the different complications between pregnant teens in Armed Forces Hospitals Southern Region, Saudi Arabia when compared to adult ones.

Methods: This retrospective case control study conducted at the Obstetrics and Gynecology Department of Armed Forces Hospitals Southern Region, Saudi Arabia from $1^{\text {st }}$ of February 2015 to $31^{\text {st }}$ of July 2017 . It included pregnant teens (13 to 19 completed years at the time of delivery) and older mothers (aged 20 to 29 years old). The studied outcomes of the study included different pregnancy complications involving both mothers and neonates.
\end{abstract}

Results: adverse pregnancy outcomes were significantly $(\mathrm{p}=0.0001)$ higher among the teen mothers. They experienced a statistically more $(\mathrm{p}=0.005)$ uneventful normal vaginal deliveries. On the other hand, older mothers showed a higher elective cesarean section delivery (CD) rate as well as instrumental delivery ( $\mathrm{p}=0.0001, \mathrm{p}=0.002$; respectively). Regarding neonatal outcomes, younger mothers had a statistically significant lower neonatal birth weight and Apgar scores when compared with the adult ones.

Conclusion: Teenage pregnancy carried clearly the risk for developing a full spectrum of adverse maternal and neonatal outcomes throughout pregnancy and labor.

Keywords: teenage pregnancy, obstetrical outcome, neonatal outcomes, maternal, adolescents, multiple contraceptives, fetal hypoxia, contradictory opinions, anemia, urinary tract infection, psychological disturbance
Volume 8 Issue 5 - 2019

\author{
Ahmed Gamal Badawie ${ }^{1,2}$ \\ 'Department of Obstetrics and Gynecology, October 6 \\ University, Egypt \\ ${ }^{2}$ Department of Obstetrics and Gynecology, University of \\ Armed Forces Hospital Southern Region, Saudi Arabia
}

Correspondence: Ahmed Gamal Badawie, department of obstetrics and gynecology, university of October 6th, Egypt, and department of obstetrics and gynecology, university of armed forces hospital southern region, Saudi Arabia, Te +201001405558, +966530485760,

Email abadawie@hotmail.com

Received: April 23, 2019 | Published: September 27, 2019
Abbreviations: STDs, sexually transmitted diseases; UTI, urinary tract infection; PTB, preterm birth; MMR, maternal mortality rate; IUGR, intrauterine growth restriction

\section{Introduction}

Teenage pregnancy becomes a raising challenge for health care professionals of developing and developed countries. ${ }^{1}$ Adolescent, also known as teenage pregnancy is affected by different variables. Its rate often attributed to the sexual activity levels, the provided sex education and ease access to multiple contraceptives between countries. $^{2}$ the literature, in general, published all over the world suggested the raise of teenage pregnancies. ${ }^{3,4}$ The double burden of reproduction as well as the progressive developmental growth among teenage pregnancies mark them as a high-risk group in reproductive terms. ${ }^{5}$ Moreover, almost $95 \%$ of teen's births are conducted in developing countries for example, Saudi Arabia's teen pregnancies ranged between $4.1 \%$ to $11.3 \%$ in urban and rural areas respectively. Factors contributing to the high teen pregnancy rate in those countries are overlapping such as; traditional, behavioral, socio-economical, educational and religious ones. Also, it seems that poverty and low socio economic status are the most prevalent factors. ${ }^{8}$

Published data discussing teenage pregnancy complications yielded contradictory opinions, and results varied. Some found that maternal age did not seem to behave as a sole risk factor, and the poor pregnancy outcomes might be explained more by lifestyle and low socio-economic standards rather than the biological basis. ${ }^{9}$ Others proved that pregnancy complications of teenage mothers significantly decreased with high-quality maternal care. ${ }^{10}$ Many unwanted maternal outcomes were significantly associated with teenage pregnancy such as sexually transmitted diseases (STDs), anemia, urinary tract infection (UTI), miscarriages, preterm birth (PTB), pregnancy-related hypertensive disorders, traumatic fistulas, postpartum adverse events, psychological disturbance, a high rate of CD and fetal hypoxia. ${ }^{11}$ Furthermore, maternal mortality rate (MMR) of pregnant teens (aged between 10-14years) showed fivefold raise than that of older mothers (between 20-24years). ${ }^{12}$ Also, there are various adverse neonatal outcomes such as risk of induced prematurity, decreased birth weight, intra-partum asphyxia, still births, respiratory distress syndrome and traumatic injuries. ${ }^{13}$ Thus, our study aimed to compare the prevalence of adverse pregnancy outcomes between teenage and adult mothers in Armed Forces Hospital Southern Region, which is the largest tertiary center in southern region of Saudi Arabia.

\section{Patients and methods}

This retrospective case control study was conducted at the Obstetrics and Gynecology department of Armed Forces Hospital Southern region, Saudi Arabia from $1^{\text {st }}$ of February 2015 to $31^{\text {st }}$ of July 2017, after being approved by the regional research ethics committee. The hospital policy was to obtain a general consent from all pregnant women at the initial visit of antenatal care that their data could be used anonymously for research purposes. Through revising the electronic files, we included women based on their age.

Teenage pregnancy was defined as pregnancy documented during the maternal age of 13 to completed 19 years at the time of delivery, ${ }^{14}$ and its data was included in the case group, while adult mothers aged between 20-29 years were considered as a control group. The age range 
of the control group was considered on the basis that this age group is agreed to be optimum for safe childbirth. ${ }^{15}$ We excluded women aged more than 30 years and those suffering a major chronic diseases such as; renal diseases, cardiopulmonary disorders, hypothyroidism, diabetes mellitus and connective tissue malformations. Women with incomplete documentation of their electronic files were also excluded.

The files were searched carefully and data collected included; complete history elements of age, parity, residency, education level, economic status and gestational age at delivery. Different medical, surgical or obstetrical outcomes noticed throughout pregnancy trimesters were recorded. Delivery outcomes were studied and recorded as the delivery mode and occurrence of postpartum side effects. Neonatal outcomes were documented including the birth weight, neonatal adverse events and mortalities. The descriptive (demographic and baseline data) were presented as mean, standard deviation and frequency as appropriate and compared using unpaired (t) and Chi-square tests between groups. The collected data were handled using Microsoft Access database software and analyzed using SPSS version 21 (SPSS Inc., Chicago, IL, USA). $\mathrm{p}<0.05$ was the marker for statistical significance.

\section{Results and Discussion}

3600 electronic files of eligible pregnant women, who presented to our hospital, were observed. Only 3556 were included in the statistical analysis. 30 women had incomplete electronic files with defective documentation of pregnancy and labor events, while 14 women did not sign the general consent upon admission, so their data were abandoned from the analysis. The socio-demographic characteristics of both groups are represented in (Table 1). Control group had significantly higher parity, more jobs occupied and higher miscarriage as well as past history of previous cesarean deliveries. Also, more women of that group were from rural areas.

Table I Socio-demographic data and past history of the study population

\begin{tabular}{llll}
\hline Characteristic & $\begin{array}{l}\text { Control } \\
\text { group }\end{array}$ & $\begin{array}{l}\text { Case } \\
\text { group }\end{array}$ & P-Value \\
\hline Age & $28.43 \pm 5.64$ & $17.49 \pm 0.63$ & $0.000 \mathrm{I}$ \\
Parity & $2.79 \pm 2.33$ & $0.53 \pm 0.79$ & $0.000 \mathrm{I}$ \\
Residence in rural area & $2529(85.7)$ & $576(95)$ & \\
Residence in urban area & $42 \mathrm{I}(\mathrm{I} 4.3)$ & $30(5)$ & $0.000 \mathrm{I}$ \\
Education & & & \\
No & $2835(96.1)$ & $597(98.5)$ & \\
Primary level & $25(0.8)$ & $3(0.5)$ & $0.01 \mathrm{I}$ \\
Secondary level & $90(3.1)$ & $6(1)$ & \\
Employment status & & & \\
Working & $96(3.3)$ & $6(1)$ & 0.001 \\
Past Abortion & $0.54 \pm 1.05$ & $0.19 \pm 0.45$ & $0.000 \mathrm{I}$ \\
Past CD & $0.66 \pm 1.01$ & $0.17 \pm 0.46$ & $0.000 \mathrm{I}$
\end{tabular}

(Table 2) shows the comparison of prevalence of obstetric complications between both groups. Although the two groups were comparable $(\mathrm{p}=0.062)$ in developing overall late pregnancy complications, specific complications were significantly higher in younger mothers as development of congenital anomalies, oligo hydramnios, intrauterine growth restriction (IUGR), eclampsia and ante partum hemorrhage. The gestational age at delivery was comparable between both groups.
Table 2 Maternal outcomes during pregnancy of the study participants

\begin{tabular}{llll}
\hline Characteristic & Control group & Case group & P-Value \\
\hline $\begin{array}{l}\text { Early pregnancy } \\
\text { complications }\end{array}$ & $294(10)$ & 579.4 & 0.275 \\
$\begin{array}{l}\text { Late pregnancy } \\
\text { Complications }\end{array}$ & $124 \mid 42.1$ & 285.47 & 0.062 \\
Gestational DM & 9 & 3 & $0.07 \mid$ \\
Gestational HTN & 117 & 24 & 0.742 \\
Preeclampsia & 224 & 42 & $0.00 I^{*}$ \\
Eclampsia & 18 & 15 & $0.000 I^{*}$ \\
\hline
\end{tabular}

Teen mothers had a higher normal vaginal delivery rate, while adult mothers had higher elective $\mathrm{CD}$ and operative vaginal delivery rates. However, a higher emergency $\mathrm{CD}$ rate with statistically significant difference was conducted to deliver the teenage group (Table 3). Postpartum morbidity between the two groups was comparable in terms of major postpartum adverse outcomes as hemorrhage, blood transfusion, hysterectomy and ICU admission. Stillbirths were significantly more common in adult mothers (Table 4). Regarding neonatal outcomes, teenage pregnancy was associated with significantly lower birth weight as well the lower Apgar scores (Table 5).

Table 3 Obstetric complications

\begin{tabular}{llll}
\hline Characteristic & Control group & Case group & P-Value \\
\hline Breech & 120 & 27 & 0.245 \\
Malpresentation & 33 & 3 & $0.002^{*}$ \\
IUGR & 21 & 9 & $0.001^{*}$ \\
Postdate & 135 & 30 & 0.156 \\
Oligohydramnios & 72 & 24 & $0.032^{*}$ \\
Congenital & 15 & 12 & $0.003^{*}$ \\
anomalies & 270 & 51 & 0.081 \\
PROM & 132 & 30 & 0.274 \\
Preterm labor & 48 & 3 & $0.002^{*}$ \\
Placenta Previa & 15 & 9 & $0.001 *$ \\
Accidental & 159 & 27 & 0.321 \\
hemorrhage & Multiple pregnancy & 159 \\
\hline
\end{tabular}

Table 4 Mode of delivery and postpartum morbidities in the study participants

\begin{tabular}{llll}
\hline Characteristic & Control group & Case group & P-Value \\
\hline $\begin{array}{l}\text { Gestational age (weeks) } \\
\text { at time of delivery }\end{array}$ & $37.39 \pm 2.99$ & $37.18 \pm 3.28$ & 0.144 \\
$\begin{array}{l}\text { Hemoglobin level(gm/ } \\
\text { dl) at time of delivery }\end{array}$ & $1 \mathrm{I} .17 \pm \mathrm{I} .56$ & $\mathrm{II} .29 \pm \mathrm{I} .50$ & 0.379 \\
$\begin{array}{l}\text { Hospital stay duration } \\
\text { (days) }\end{array}$ & $\mathrm{I} .64 \pm 2.62$ & $\mathrm{I} .34 \pm \mathrm{I} .42$ & $0.007^{*}$ \\
$\begin{array}{l}\text { Elective CS } \\
\text { Emergency CS }\end{array}$ & $1035(39)$ & $129(23.5)$ & $0.000 \mathrm{I}^{*}$ \\
Ventouse & $697(26.2)$ & $195(35.5)$ & $0.000 \mathrm{I}^{*}$ \\
Vaginal delivery & $\mathrm{I} 5(0.6)$ & 0 & $0.002^{*}$ \\
\hline
\end{tabular}


Table continued

\begin{tabular}{llll} 
Characteristic & Control group & Case group & P-Value \\
\hline PPH & $60(2)$ & $12(2)$ & 0.938 \\
Rupture uterus & 3 & 0 & 0.128 \\
Hysterectomy & $2 I(0.7)$ & $\mathrm{I}(0.2)$ & 0.291 \\
Blood transfusion & $\mathrm{I} 89(6.4)$ & $48(7.9)$ & 0.217 \\
ICU admission & $63(2.1)$ & $\mathrm{I}(2)$ & 0.13 \\
\hline
\end{tabular}

Table $\mathbf{5}$ The neonatal outcomes of the study participants

\begin{tabular}{llll}
\hline Characteristic & Control group & Case group & P-Value \\
\hline Living & $2557(96.6)$ & $537(97.8)$ & $0.00 I^{*}$ \\
Dead & $99(3.4)$ & $12(2.2)$ & \\
NICU admission & $44 I(14.9)$ & $108(19.7)$ & 0.177 \\
Apgar score & $9.42 \pm 1.48$ & $9.21 \pm 1.83$ & $0.004^{*}$ \\
\hline
\end{tabular}

\section{Conclusion}

Teenagers' maternal morbidity and mortality seemed to be a crucial public health issue worldwide. ${ }^{16}$ Our data revealed that the incidence of adolescent among women following in Southern Region is high (about $17 \%$ of overall pregnancies). Oligohydramnios and IUGR were significantly higher among young mothers; whereas, postpartum incidents were higher in the adult ones. Teen mothers showed significantly more normal vaginal deliveries, while instrumental intervention and elective $\mathrm{CD}$ were statistically more needed for older mothers.

$17 \%$ was the incidence of teenage pregnancy in the recent work and most of those live in rural areas. Al-Haddabi et al. ${ }^{17}$ reported almost same range (16-18\%) as our data about teenage mothers, while, Kumar et al. ${ }^{18}$ showed lower incidence of adolescent pregnancy of about $4 \%{ }^{18}$ This might be due to the discrepancy of small sample size of the two studies, 1476 women recruited by them compared to 3556 women in ours. However, Sweden reported less than 3\% teenage pregnancy of overall live births and could be attributed to the high socioeconomic level of the country.

Almost all teen pregnant women were unemployed (99\%). On the other hand, (96.7\%) adult women presented lower unemployment rate. Kaisa et al. ${ }^{19}$ also reported, a same finding, that older mothers significantly worked more than younger ones $(83.1 \%$ versus $62.45 \%) .{ }^{19}$ Other reports noticed that the pregnancy-related hypertension were higher with teenage pregnancy. ${ }^{20-21}$ In accordance to that, the present work showed that eclampsia solely was significantly higher between teen mothers. This could be explained by the fact that a lot of teen pregnant women occupied rural areas that suffered from lack of proper antenatal follow-up which leaded majority to develop late pregnancy hypertensive disorders' complications as eclampsia. Thus, it could raise the attention that the young mothers were less careful and aware about pregnancy care and its impact on their general health.

Ziadeh et al. ${ }^{22}$ concluded that maternal age was not a contributing factor in developing antepartum hemorrhage as there was no difference between his groups. ${ }^{22}$ However in the present work, placenta prevail significantly resulted in higher incidence of ante partum hemorrhage. The fact that adult mothers showed significantly higher parity than the teenage counterparts could explain this observation. In accordance with our results, Derme et al..$^{23}$ reported that oligohydramnios and premature rupture of membranes (PROM) as the commonest maternal obstetric complication, while IUGR was the commonest fetal incident in teenage pregnancy. ${ }^{23}$ Normal vaginal delivery was the statistically significant mode of delivery for teenagers who underwent more vaginal deliveries than cesarean deliveries or instrumental deliveries performed on adults. These observations were consistent with previously published data of Derme et al. ${ }^{23}$ and Abdelsattar et al. ${ }^{23-24}$ these could be attributed to a better myometrial contractility, more elastic connective tissue and lower cervical compliance.

Furthermore, Ezegwui et al. ${ }^{25}$ and Nwobodo et al. ${ }^{26}$ reflected a significant increase in conducting emergency $\mathrm{CD}$ among teenage mothers when compared to older mothers which was also confirmed by our study. ${ }^{25,26}$ The family size could increase due to teenage pregnancy especially with shorter inter-pregnancy intervals and longer marital life. This eventually might lead to impaired nutritional status of adolescent mothers gaining higher risks in their future pregnancies particularly those with overlap period between pregnancy and lactation, ${ }^{27}$ there was no statistical significant difference between teenage and adult mothers regarding adverse postpartum events. However, postpartum hemorrhage complicated 12(2\%) teenage mothers with its subsequent management of blood transfusion and peripartum hysterectomy. A previous study reported that nearly $6 \%$ of emergency peripartum hysterectomies were necessary to save lives of teenage mothers. ${ }^{28}$ In addition, $5.2 \%$ of overall maternal mortality was associated with teenage pregnancy. ${ }^{29}$

Although conducting the study in a tertiary care hospital allowed good sample size, chances of having more high-risk pregnant women could be considered as a limitation of the study. Thus, it might not be actually representative of the current situation in overall community setting. Moreover, it was expected that good proportion of young age mothers would not be able to strictly follow-up to ignorance, poverty or social reasons.

To sum up, the current work clearly demonstrated that the young maternal age could carry higher risk for teen mothers and their neonates to develop obstetric complications or neonatal morbidities respectively. New strategies to reduce the prevalence of teenage pregnancy should be designed and implemented especially in developing countries. Providing health education, improving the health and nutrition of the female child, postnatal contraception should be encouraged for proper inter pregnancy spacing to avoid unwanted pregnancies that might raise more financial and emotional stability.

\section{Acknowledgments}

None

\section{Conflicts of interest}

The author declares that there are no conflicts of interest.

\section{References}

1. Veena SR, Gale CR, Krishnaveni GV, et al. Association between maternal nutritional status in pregnancy and offspring cognitive function during childhood and adolescence; a systematic review. BMC Pregnancy Childbirth. 2016;12;216-20.

2. Egbe TO, Omeichu A, Halle-Ekane GE, et al. Prevalence and outcome of teenage hospital births at the Buea Health District, South West Region, Cameroon. Reprod Health. 2015;23;112-128.

3. Zhou Y, Puradiredja DI, Abel G. Truancy and teenage pregnancy in English adolescent girls: can we identify those at risk? J Public Health (Oxf). 2016;38(2):323-329. 
4. Dutta I, Joshi P. Maternal and perinatal outcome in teenage vs. Vicenarian primigravidae-a clinical study. J Clin Diagn Res. 2013;7(12):28812884 .

5. Goossens G, Kadji C, Delvenne V. Teenage pregnancy: a psychopathological risk for mothers and babies? Psychiatr Danub. 2015;27(1):S499-S503.

6. Yasmin G, Kumar A, Parihar B. Teenage pregnancy-its impact on maternal and fetal outcome. International Journal of Scientific Study. 2014;1(6):9-13.

7. Mersal FA, Esmat OM, Khalil GM. Effect of prenatal counselling on compliance and outcomes of teenage pregnancy. East Mediterr Health J. 2013;19(1):10-17.

8. Moisan C, Baril C, Muckle G, et al. Teen pregnancy in Inuit communities - gaps still needed to be filled. Int J Circumpolar Health. 2016;9;75:317319.

9. Blackman K. Evidence-Based Policies to Prevent Teen Pregnancy. NCSL Legisbrief. 2016;24(16):1-2.

10. Marino JL, Lewis LN, Bateson D, et al. Teenage mothers. Aust Fam Physician. 2016;45(10):712-717.

11. Coyne CA, D’Onofrio BM. Some (but not much) progress toward understanding teenage childbearing: a review of research from the past decade. Adv Child Dev Behav. 2012;42:113-152.

12. Chandra-Mouli V, Camacho AV, Michaud PA. WHO guidelines on preventing early pregnancy and poor reproductive outcomes among adolescents in developing countries. $J$ Adolesc Health. 2013;52(5):517522.

13. Hadley A, Ingham R, Chandra-Mouli V. Implementing the United Kingdom's ten-year teenage pregnancy strategy for England (19992010): How was this done and what did it achieve? Reprod Health. 2016;22;13(1):139.

14. Leal I, Luttges C, Troncoso P, et al. The legal framework to prevent teenage pregnancies. Rev Med Chil. 2016;144(5):577-584.

15. Rogue F. Teenage pregnancies, legal aspects. Soins Pediatr Pueric. 2016;37(291):19-21.

16. Lara D, Decker MJ, Brindis CD. Exploring how residential mobility and migration influences teenage pregnancy in five rural communities in California: youth and adult perceptions. Cult Health Sex. 2016; 18(9):980-995.
17. Al-Haddabi R, Al-Bash M, Al-Mabaihsi N, et al. Obstetric and perinatal outcomes of teenage pregnant women attending a tertiary teaching hospital in oman. Oman Med J. 2014;29(6):399-403.

18. Kumar A, Singh T, Basu S, et al. Outcome of teenage pregnancy. Indian J Pediatr. 2007;74(10):927-931.

19. Raatikainen K, Heiskanen N, Verkasalo PK, et al. Good outcome of teenage pregnancies in high-quality maternity care. Eur J Public Health. 2006;16(2):157-561.

20. Saxena P, Salhan S, Chattopadhyay B, et al. Obstetric and perinatal outcome of teenage and older primigravidas-a retrospective analysis. Health and Population. 2010;33(1);16-22.

21. Chahande MS, Jadhao AR, Wadhva SK, et al. Study of some epidemiological factors in teenage pregnancy-hospital-based case comparison study. Indian Journal of Community Medicine. 2002;27(3):106-109.

22. Ziadeh S. Obstetric outcome of teenage pregnancies in North Jordan. Arch Gynecol Obstet. 2001;265(1):26-29.

23. Derme M, Leoncini E, Vetrano G, et al. Obstetric and perinatal outcomes of teenage pregnant women: a retrospective study. Epidemiology Biostatistics and Public Health. 2013;10(4).

24. Abdelsattar M. Teenage pregnancy in Upper Egypt. Int J Adv Res Biol Sci. 2016;3(4):35-41.

25. Ezegwui HU, Ikeako LC, Ogbuefi F. Obstetric outcome of teenage pregnancies at a tertiary hospital in Enugu, Nigeria. Niger J Clin Pract. 2012;15(2):147-50.

26. Nwobodo EI, Adoke KU. Obstetric outcome of teenage pregnancies at a tertiary care hospital in Sokoto, Nigeria. Trop J Obstet Gynaecol. 2005;22(2):168-170.

27. Shaaban OM, Abbas AM, Abdel Hafiz HA, et al. Effect of pregnancylactation overlap on the current pregnancy outcome in women with substandard nutrition: a prospective cohort study. Facts Views Vis Obgyn. 2015;28;7(4):213-221.

28. Abbas AM, Abdelbadee AY, Amin MT, et al. Emergency peripartum hysterectomy in a tertiary hospital in Upper Egypt: six years analysis. Int J Reprod Contracept Obstet Gynecol. 2016;5(4):953-958.

29. Abbas AM, Amin MT, Ali SS, et al. Maternal mortality: a tertiary care hospital experience in Upper Egypt. Int $J$ Reprod Contracept Obstet Gynecol. 2016;5(5):1466-1471. 